\title{
Entertainment Technology: Dynamic Game Production
}

\author{
Yogi Udjaja*
}

Computer Science Department, School of Computer Science, Bina Nusantara University, Jakarta, 11480, Indonesia

\begin{tabular}{l} 
A R T I C L E I N F O \\
\hline Article history: \\
Received: 27 March, 2020 \\
Accepted: 06 June, 2020 \\
Online: 22 July, 2020 \\
\hline
\end{tabular}

Keywords:

Dynamic Game Production

Game Development

Software Engineering

\begin{abstract}
A B S T R A C T
The times have made drastic changes in the field of technology, these changes have penetrated into various aspects, one of which is the game. Starting from the tactics of war in the real world that produces the game theory, then adopted in the form of games that exist today. Starting from without visuals to extraordinary visual elements, each of these changes always changes the way game developers in terms of making games, so that proposed methods that can adjust to the development era that can maintain quality and interest of users so that the game is made right on target, namely Dynamic Game Production.
\end{abstract}

\section{Introduction}

Game theory was first discovered in 1944 by Neumann and Morgenstern, where the theory was adopted for war strategy [1]. On the other hand, in 1958 found the first computer-based game (digital game) made by Higinbotham and named Tennis for Two [2], this development changed history, so the way of making games also developed.

In general, the development of the game is directly proportional to the development of technology. It can be seen from the beginning of the game formed, starting from the model of the game that was played without visual elements until now the game has a visual element that is extraordinary. Developments that occur not only visualization but as a whole, so that the way of making it from time to time is also increasingly developing.

Then in 2005 the game development life cycle (GDLC) method was born which served to improve the quality of the game. According to Aleem et al., there are 5 continents in the spotlight on GDLC research, namely: Asia, Europe, North America, South America and Australia [3]. Total research on GDLC from 5 continents is around 296 studies both from pre-production, production to post-production stages. Aleem et al. said the quality of game development is still immature because there are still very few activities in game research especially in post-production [3]. Based on research that has been done, making a game requires

*Yogi Udjaja, Jakarta, Indonesia 11480, +62 8982683399 ,

udjaja.yogi@gmail.com,yogi.udjaja@binus.ac.id systematic investigation, where the games are made whether it is in accordance with the desires and needs of players [4].

This can be taken based on several factors that support the player's interest, including the most important is the psychological aspect. Based on this interaction with the user or player is very important to improve the quality of the game made.

\section{Related Research}

\subsection{Game Production Pipeline}

GameDev Jakarta is a game developer community located in Jakarta, Indonesia. Based on the results of discussions from the GameDev Jakarta Gathering (2016) obtained three main processes in making games, namely: pre-production, production and post-production.

- $\quad$ Pre-production: Stages before making a game, in the form of concepts, data analysis and game design.

- Production: The stages of making the following games are alpha and beta testing.

- Post-Production: Stages after the game is finished and marketed. When it has been marketed or released, the game's performance is checked again, is it feasible to maintain or make a new version or if the performance is not in accordance with what is desired, the game is not developed anymore (abandon).

\subsection{Game Development Life Cycle}

Ramdan and Widyani analyzed several game development life cycle (GDLC) models performed by Blitz Game Studios, Arnold 
Hendrick, Doppler Interactive and Heacher Chandler [5]. Then after analyzing the GDLC model, the new GDLC model was proposed, in accordance at that time. After re-analysis $[5,6]$, there are still many things that need to be improved from this method, therefore this study was made.

\subsection{Game Development Based Learning}

Game development based learning (GDBL) is used to increase motivation and overall productivity of players [7]. In general it can be seen the relationship between serious games, game based learning, gamification and GDBL (see figure 1).

In figure 1 explained that the serious game is as a whole of a game that has a goal that involves all aspects of teaching, training and providing information. Game based learning (GBL) is a serious game created to improve teaching activities and initiatives based on role-playing, motivation, involvement and repetition. While gamification is the application of game elements in a nongame context. Then it can be concluded that GDBL is making games by combining all aspects contained in serious games, GBL and gamification.

According to Spieler and Slany, in stages GDBL was developed in 4 stages viz [7]:

- Research: This stage is carried out data collection, investigation and analysis of the story, title, genre and theme of the game, as well as the basic concepts of game structure and gameplay.

- Design: This stage creates a game design document that contains artwork, game content, and other game elements (assets, characters, sound, etc.).

- Development: This stage covers all the processes of making game elements, programming and followed by testing.

- Release: This stage is the last stage when the game is finished and is running well.

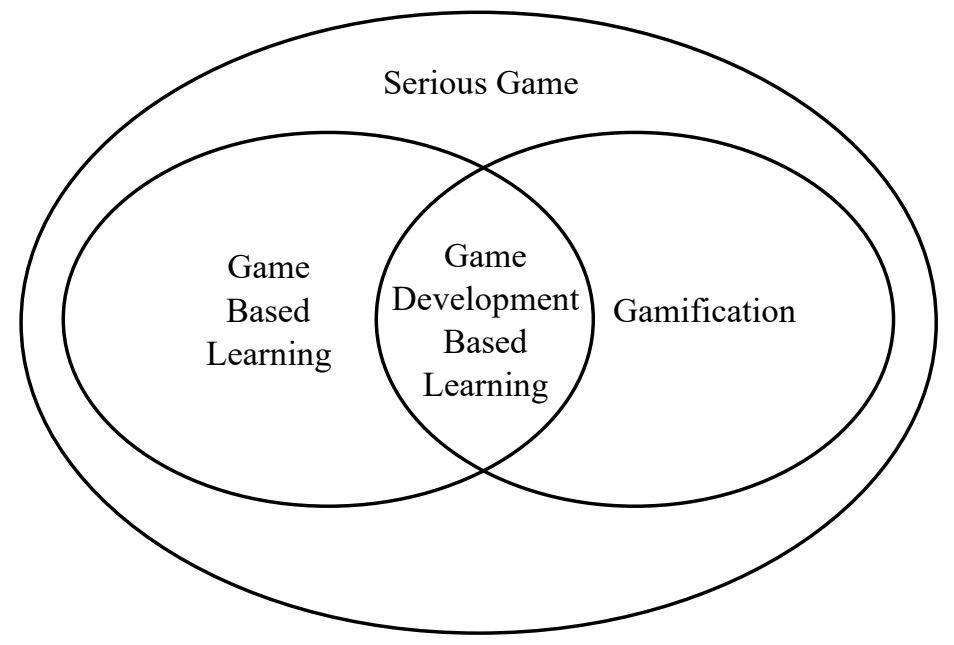

Figure 1: Relationship between Serious Game, GBL, gamification and GDBL [7]

\subsection{Challenge Based Learning}

Challenge Based Learning (CBL) is one way to learn so that someone can think critically $[8,9]$. Where in this method begins with a real problem and collaborates with the team to get the best solution.

\subsection{Interpersonal Circumplex}

According to Isbister, Interpersonal circumplex can be used as a model to recognize the player's personality or to make expressions, traits, culture, social activities and other personalities of characters in the game [10]. These models can be used to determine the target player and market research of the game to be made.

\subsection{Game Experience}

Based on the explanation from Udjaja, game experience comes from a combination of user interface (UI), user experience (UX), gameplay experience (GX) and game balancing [11]. The model has been proven to see conformity to the comfort, interests, needs and motivation of users to play.

\section{Propose Method}

Based on previous research [4-16], game development methods always change dynamically as needed. Based on this, the proposed game development method was developed according to the needs and changing times of the dynamic game production (DGP). This method looks at the emotional engagement aspect of the player so that the game is made right on target. The following are the DGP stages (see figure 2):

\section{A. Initiation}

This stage is a determinant of the suitability of making a game to suit the needs of the player. In this stage, the analysis phase can be done simultaneously or alternately, so as to produce the required system requirements. The stages are:

- Player Analysis

At this stage an analysis of player needs and payer motivation to play the game, as well as the determination of the game concept.

- Competitor Analysis

At this stage an analysis of existing games is performed. Can be seen from the manufacturing process, marketing to game maintenance.

- Interaction Analysis

At this stage an analysis of the interaction will be performed by the player. Can be seen from the device and controller used, and how to use it.

\section{- System Requirement}

After conducting the analysis, the results of the analysis are formed into a system requirement. This stage is the required requirements. Can be made using mind maps or other methods that are easily understood by developers.

Stages of analysis carried out can use the CBL method so that the results obtained are right on target. For workmanship guidelines can be seen in ref. [16]. 


\section{B. Alpha Version}

This stage is carried out alternately, starting from preproduction, then proceed with production and prototype testing, the prototype is evaluated through performance analysis, when the results of the prototype testing are not in accordance with the requirements then the preproduction stage will be carried out again or can return to the initiation stage.

\section{- Preproduction}

Based on the system requirements that have been made, an estimated time of manufacture is made. Then the game design document (GDD) is made, which contains the design of the game to be made, as has been made by Adams [17]: high concept document, game treatment document, character design document, world design document, user interface design document, flowboard, story and level progression, on-screen text and dialog script, game script. In GDD can also be added specific design in the form of game experience, in-game algorithm, artificial intelligence, debug system, system design using object oriented or procedural and so on. The more detailed design that is made, the clearer the flow of the game to be made.

\section{- Production}

At this stage the game is made based on the existing GDD. Making a game is divided into several modules, according to the system requirements and estimated time that has been made. Every single title was completed, a play was tested and a work checklist was made.

\section{- $\quad$ Prototype Testing}

After the prototype game is finished making automatic testing using Selenium or other applications to see if there are errors in the code that has been made. Besides that, playtesting is also done internally and added by some people from external (can be from players or people who are experts in their field) to get feedback on the interest in game and game experience. Then a performance analysis is performed, where the results of automatic testing and feedback from people who have done the testing are analyzed and compared with the GDD that is made, so that the quality of the game made can be increased again. If it is not in accordance with the expectations or the GDD made there is an error done again initiation stage.

\section{Beta Version}

This stage was performed soft-launch playtesting to several players, then performance analysis was re-conducted. When there is a mismatch, changes will be made at the production stage, otherwise it will be returned to the initiation stage.

\section{Release}

This stage is the stage of launching the game to the public. player research analitic is done to see the player's interest, if there is a monetize can also be seen from items that are often purchased or from the revenue obtained.

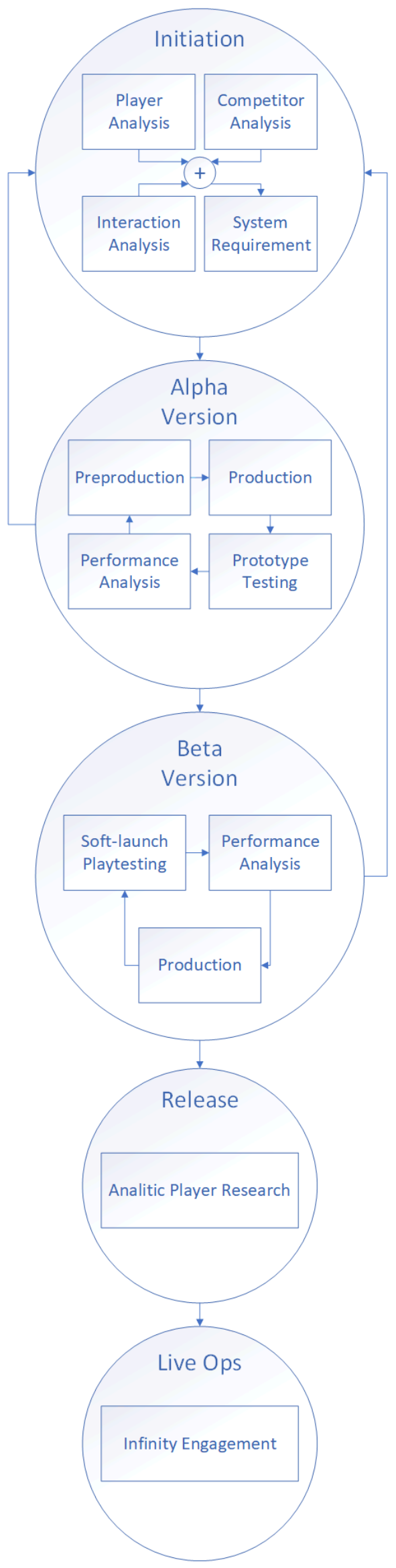

Figure 2: Dynamic Game Production 


\section{E. Live Ops}

This stage is the stage of maintaining player interest in continuing to play games that have been live by making changes in the game. In general, this change does not change the code that has been made, if you change the code, changes made in a small scope or add some new functions. Changes that occur can be made such as adding cosmetic items, limited offers, new mechanics, camapign to acquire paid users or others.

\section{Conclusion and Discussion}

Every making something should begin with research so that what is made right on target. One simple concept like $5 \mathrm{~W} 1 \mathrm{H}$ (What, Where, When, Who, Why, How) can be used to understand something, or combined with challange based learning.

This DGP was created to maintain the quality of the game and the interests of the players so that the game was made right on target. In practice, this method is a method of making a dynamic game, when there is a change from a condition, this method is able to adjust and solve it - such as the alpha version or beta version can return to initiation (See figure 2), so that the results of the game are made better.

On the other hand, emotional engagement in games has positive and negative impacts, when getting someone's emotional engagement, playing games can change one's behavior. It also must be considered, whether this change is good or not. The developer must also consider this so that undesirable things do not happen.

\section{References}

[1] J.V. Neumann, O. Morgenstern, "Theory of games and economic behavior (commemorative edition) " Princeton university press, 2007.

[2] W. Higinbotham, "Tennis for two, 1958. https://www.sunysb.edu/libspecial/videogames/tennis.html

[3] S. Aleem, L.F. Capretz, F. Ahmed, "Game development software engineering process life cycle: a systematic review. Journal of Software Engineering Research and Development, 4(1), 6, 2016. https://doi.org/10.1186/s40411-016-0032-7

[4] Y. Udjaja, V.S. Guizot, N. Chandra, "Gamification for Elementary Mathematics Learning in Indonesia. International Journal of Electrical and Computer Engineering (IJECE), 8(6), 2018. http://doi.org/10.11591/ijece.v8i5.pp3860-3865

[5] R. Ramadan, Y. Widyani, "Game development life cycle guidelines", In Advanced Computer Science and Information Systems (ICACSIS), 2013 International Conference, 2013. https://doi.org/10.1109/ICACSIS.2013.6761558

[6] Y. Udjaja, A.C. Sari, "A Gamification Interactive Typing for Primary School Visually Impaired Children in Indonesia", Procedia computer science, 116, 638-644 2017. https://doi.org/10.1016/j.procs.2017.10.032

[7] B. Spieler, W. Slany, "Game Development-Based Learning Experience: Gender Differences in Game Design, 2018. arXiv preprint arXiv:1805.04457.

[8] L. Johnson, S. Brown, "Challenge based learning: The report from the implementation project, 1-36, 2011.

[9] The Challenge Institute "Challenge Based Learning Viewed on 20 October 2019 18:56 WIB, 2018. Retrived on: https://www.challengebasedlearning.org

[10] K. Isbister, "Better game characters by design: A psychological approach. San Francisco: Elsevier, 2006.

[11] Y. Udjaja, "Gamification Assisted Language Learning for Japanese Language Using Expert Point Cloud Recognizer. International Journal of Computer Games Technology, 2018. https://doi.org/10.1155/2018/9085179

www.astesj.com
[12] D.P. Kristiadi et al., "The effect of UI, UX and GX on video games", In Cybernetics and Computational Intelligence (CyberneticsCom), 2017 IEEE International Conference, 158-163, 2017. https://doi.org/10.1109/CYBERNETICSCOM.2017.8311702

[13] Y. Udjaja et al., "The Use of Role Playing Game for Japanese Language Learning." Procedia Computer Science 157, 298-305, 2019. https://doi.org/10.1016/j.procs.2019.08.170

[14] S.A. Halim et al., "The Repercussions of Game Multiplayer Online Battle Arena. In 2019 International Conference of Artificial Intelligence and Information Technology (ICAIIT), 443-447, 2019. https://doi.org/10.1109/ICAIIT.2019.8834518

[15] S. Harsono et al., "The Effect of Game Experience from Counter-Strike: Global Offensive. In 2019 International Conference of Artificial Intelligence and Information Technology (ICAIIT), 374-378, 2019. https://doi.org/10.1109/ICAIIT.2019.8834521

[16] Apple, Challenge Based Learning: A Classroom Guide. Viewed on 20 October 2019 18:29 WIB, 2010. Retrived on: https://images.apple.com/education/docs/CBL_Classroom_Guide_Jan_20 11.pdf

[17] E. Adams, "Fundamentals of game design. Pearson Education, 2014. 